\title{
Hantaviruses: A Global Life Threatening Disease
}

\author{
Suruchi Agarwal*, Mamta Kumari, Anupam Kr Sachan \\ Dayanand Dinanath College, Institute of Pharmacy, Ramaipur, Kanpur Nagar-209214, Uttar Pradesh, India.
}

\author{
ARTICLE INFO: \\ Received: 10 Feb 2021 \\ Accepted: 20 Feb 2021 \\ Published: 28 Feb 2021 \\ Corresponding author * \\ Suruchi Agarwal, \\ Dayanand Dinanath College, \\ Institute of Pharmacy, Ramaipur, \\ Kanpur Nagar-209214, Uttar \\ Pradesh, India. \\ E Mail: \\ agarwalsuruchi95@gmail.com
}

\begin{abstract}
:
Hantaviruses is an overall rat-borne infection, which has a place with family Bunyaviridae. It essentially causes two clinical symptoms Hantavirus pulmonary syndrome and hemorrhagic fever with renal syndrome. This virus is transmitted from rat to human through inhalation of rodent urine, feces, bite, or dead body. When rats drop their urine, saliva or feces the virus contaminate the air and is inhaled by the person. The person breathes the contaminated air while breeding, aerosols inhalation or excreta so it is also called as air-borne transmission. This virus does not show any appearance on natural hosts but a human related pathogen. It has more than twenty spices of rodent-borne virus, which are negative sense single strand RNA genome. The four spices of natural hosts are deer mouse, white footed mouse; cotton rat and rice rat is main carrier of Hantavirus, which are found in rural areas. It is a zoonotic disease by persistent infection. It was first isolated in America as old and new Hantavirus. It is feverish disease followed by headache, respiratory problems, myalgia, hypotension, cardiovascular disease, hypoxia, back pain, and pulmonary disease. Large, medium, and small sections are found in RNA genome. The replicated enzyme is found as large fragment, medium has envelope glycoprotein, and small has nucleocaspid $\mathrm{N}$.
\end{abstract}

Keywords: Hantavirus, rodent-virus, inhalation, RNA genome, contaminated, zoonotic.

\section{INTRODUCTION}

Hantavirus is a rodent-borne virus, which is transmitted through inhalation, breeding, contaminated air, aerosols of rodent excreta, urine, or saliva. 14 types of viruses belongs this Bunyaviridae family that causes hemorrhagic fever with renal syndrome and Hantavirus pulmonary syndrome. This virus emerges due to environmental conditions that enhance infection in human. Hantavirus is globally increasing from natural host and human-to-human spread to cause disease. It causes respiratory problem and 150000 to 200000 cases are observed all over the world. The patient sera react with hantaviral antigen by identifying genetic material of new patient tissue suffering from hantavirus and rodents are trapped. This illness has been first recognized in china is now marketed globally. When the war of Korea was going on soldiers felt with feverish illness and kidney failure. This was closely monitor, virus named on the river haantan, which has passage for rodent host. This virus is spherical in shape has diameter $100 \mathrm{~nm}$. It is surrounded by bilayer membrane made up of nucleocaspid. The projections are made of two glycoproteins G1 and G2. Hantavirus mainly does not work by exposure on heat, organic solvents such as alcohol, and detergents. The genome comprises of large segment for viral transcriptase, medium segment for polyprotein and small segment for nucleocaspid protein. Hantavirus mainly effect on adult human kidney, saliva, liver or respiratory region $[1,2,3]$. \section{HANTAVIRUS \\ 2. GENOMIC STRUCTURE OF} Hantavirus is negative RNA virus strand, which has threesegmented code with virus RNA polymerase, glycoprotein, and nucleocaspid protein. The viral glycoprotein fixed with lipid cover of dependent RNA polymerase and nucleocaspid. It starts replicating in cytoplasm and RNA dependent RNA polymerase synthesize L, M and S segment (Figure 1). In Hantavirus, nucleocaspid protein is lavish to synthesize after infection. Hantavirus nucleocaspid protein is shown in next 6 hours in cytoplasm. It may meet host cell protein such as Andes virus $\mathrm{N}$ protein contact with antiviral protein produced by cells that has been invaded by virus. For replication of virus and host cell, it should encounter with host cell protein. It may hold back the action of protein against virus host cell and stop contagious cell death. Host cell interrelate with Hantavirus $\mathrm{N}$ protein to circumvent $\mathrm{N}$ protein to take part in virus duplication $[4,5]$. 


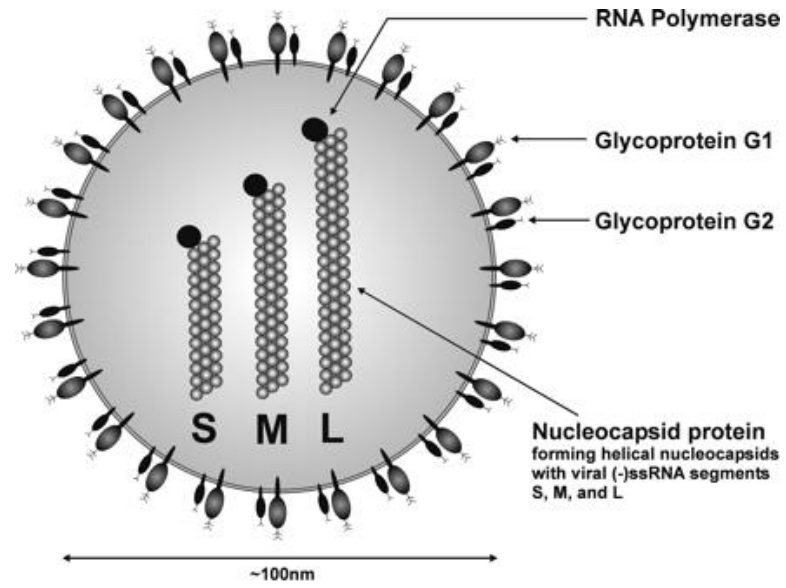

Fig 1: Hantavirus (Walter Muranyi, Udo Bahr,et al.2005)[6]

Glycoproteins are mainly found on ribosome confine to endoplasmic reticulum. The peptides give signal to ease transfer of glycoprotein precursor into endoplasmic reticulum Inside the ER, glycoprotein precursor is cleaved into G1 and G2 at preserve amino acid segment. When endoplasmic reticulum has $\mathrm{G} 1$ or G2, it does not move to Golgi bodies. Glycoprotein enters Golgi when G1 and G2 are expressed to each other. It leads to formation of G1 and G2 complex and become prepared for virus particle gathering. Endosome in acidic environment Hantavirus particle get exposed the viral and endosomal membrane is fused. The replication of hantavirus starts as viral and endosomal membrane fuse in cytoplasm. Transcriptase, endonuclease, replicase and helicase like action constitute RNA dependent RNA polymerase hence replication and transcription start. The endonucleolytic cleavage of RNA host cell is enhanced by RNA dependent RNApolymerase. It has binding site for genome RNA and host and replication of virus is initiated $[7,8]$.

\subsection{Ecology}

Hantavirus infection is getting infectious over general wellbeing and everywhere on the world in recent years. It is relationship of natural rodent and human diversity spreads in ecology due to domain factors, behavior establishment, and interaction of human and animal. There are mainly three species are field mouse for hantaan virus in Asia, the deer mouse for sin nombre virus in North America and Puumala virus in Europe. Due to changes in rodent's inhabitant, disease causing agent, territory factors, or climate changes may lead to outbreak of Hantavirus infection. An abundant scarcity of food limit to enhance the population of field mouse they depend on farm crops through they affect in human growth. Hantavirus is causing disease in human, which is noxious from placid to critical. The climatic change in environment is influencing the component of Hantavirus and viral disease in humans. The climatic condition has low effect on Hantavirus but due to this host, population is enhanced and this cannot be constrained. Human changes to scenery also increase the growth of natural host during building of farms, roads, urban centers or to forest. This movement not only changes the countryside but also increase the contact between man and natural rodent host. The surrounding due to human disorder increase the widespread within the biosphere. Breakout of hantaviral illness have been related with changes in rat populace densities, which may fluctuate incredibly across time, both occasionally and from year to year. Cycles react to such outward factors as interspecific rivalry, climatic changes, and predation. Spring and summer scene of HFRS in cultivating settings in Asia and Europe are associated to human contact with field rodents through the planting and gathering of harvests $[9,10,11]$.

Hantavirus occurs by natural host species lead to theory that disorder habitat will nurture more effect on change in behavior of rodent host enhance frequent communication of virus to human. Most of the research this theory is proved more disorder more widespread in rodent host. The changes in topography lead to less Hantavirus frequent if territory is not suitable for host as study. Human territory is disorder by storage facility or household activities such as grooming, cleaning, and vacuum cleaning inhaling rodent waste which enhance the chance of communication to humans. The indoor activities, residence, restricted humidity, and temperature are indirect mode of communication. The rodent host keeps migrating within indoor buildings from region of excreta and urine, which increase the cause of indirect communication of Hantavirus in humans[12,13].

Epidemiologic examinations have connected infection presentation to such exercises as hefty ranch work, sifting, dozing on the ground, and military activities. Indoor presentation was connected to attack of homes by field rodents during chilly climate or to settling of rodents in or close to abodes. Hereditary sequencing of rat and patientrelated infections has been utilized to pinpoint the exact areas of human diseases, which has upheld the job of indoor presentation in hantavirus transmission Numerous hantavirus contaminations have happened in people of lower financial status since more unfortunate lodging conditions and horticultural exercises favor nearer contact between people and rodents. In any case, suburbanization, wild outdoors, and other outside recreational exercises have spread contamination to people of center and upper earnings[14,15,16].

\subsection{Epidemiology}

It is notable that, the geographic dispersion and the study of disease transmission of hantaviruses reflect the dispersion and characteristic history of their essential rat. Hantaviruses principally cause asymptomatic disease in their characteristic rat has, though contamination in other creature has is thought of to be an overflow disease which in people can bring about a genuine intense ailment. It is accepted that people obtain disease by breathing in infection sullied airborne. When in doubt, people can just get contaminated after direct contact with tainted rodents or their excreta; in any case, there has been a recorded instance of ANDV being spread from 
International Journal of Pharma Research and Health Sciences, 2021; 9 (1): 3280-3285

individual to-individual. In spite of the fact that there is other possible proof of ANDV sent from individual to individual, the case referenced previously remains the main recorded instance of flat transmission of hantavirus contamination in people[17, 18].

In the Old World, there are two primary areas where most of the Hantavirus cases are enlisted: Europe and Eastern Asia (China, Korea and Russia). More than 1,00,000 HFRS cases are enlisted yearly in China and roughly 900 cases are accounted for in Korea. In Europe, most of HFRS cases are enrolled in Russia (3000 cases), Sweden (300 cases) and 100 or then again less in other European nations. Hantavirus immune response seroprevalence in the endemic territories differs from 20-45\%. Most of HFRS patients are 20 to 50 years old. Generally, a higher number of male patients are enrolled contrasted with females. The death rate changes from $0.1 \%$ to $10 \%$ contingent upon the infection. Most of HFRS cases happen in provincial territories[14,19].

Hence, HFRS turns into a word related risk for ranchers, woodland laborers, shepherds, woodcutters, military faculty, and so forth. In spite of the fact that occasional pinnacles of HFRS cases change contingent upon hantavirus included, they generally match with expanded human rural exercises in spring and fall. For instance, most of HTNV and PUUV related cases happen in the fall, while the greater part of the Dobrava infection caused HFRS cases are enlisted in the pre-summer and summer. In spite of the fact that hantavirus cases are enrolled every year, huge PUUV related episodes are identified each 3-4 years. Enormous flare-ups are normally related with an expanded populace size and structure of the bank vole (Clethrionomys glareolus), the fundamental characteristic rat have for PUUV [20,21].

The regular condition of the rat populaces may influence the size of the hantavirus ailment flare-ups in people. For instance, it has been demonstrated that each 2-3 years bank voles have two litters in one season. Rodents of the main litter, conceived in the early spring or pre-spring, go through quick turn of events and become ripe in the exact year. Creatures of the subsequent litter, brought into the world pre-summer or midsummer, become rich the following year. The level of antigen and immunizer positive mice is higher among those of the primary litter contrasted with creatures of the second litter. Accordingly, it has been recommended that creatures of the first age could be the significant supply for hantavirus in bank voles. This age may drive an industrious method of disease and protect infection starting with one zoonotic cycle then onto the next. In fact, the significant episodes of human Hantavirus contamination match with years when bank voles have two litters in one year[22,23].

Just $0.2-0.5 \%$ of the Unites States general populace was discovered to be hantavirus immune response positive. Apparently, HPS in North America are related with expanded populaces of the deer-mouse Peromyscus maniculatus, an essential rat host of SNV. The pinnacle of human HPS cases happens in the pre-summer or late spring with equivalent female-to-male proportions. Studies in South America uncovered a low seroprevalence in solid benefactor populaces in Brazil. In any case, in Argentina seroprevalence changes from $0.1-1.5 \%$ in the focal and south Argentina to $20 \%$ or more in the north piece of Argentina. Another examination exhibited that up to $40 \%$ of the Paraguayan Indians had hantavirus antibodies. Along these lines, ant hantavirus seroprevalence in people obviously relies upon the specific hantaviruses circling in the territory, their capacity to cause seroconversion in people without causing intense malady just as natural conditions, for example, lodging and introduction to rodents[19, 24].

\section{PATHOGENESIS}

Right now, there is no single factor recognized to clarify the intricacy of the etiology of HFRS furthermore, HPSHantavirus diseases of rodents are ordinarily persistent and were recently thought to be asymptomatic in their characteristic rat has, as expressed in various surveys of hantavirus science. Be that as it may, fresher examinations show that in any event New World hantaviruses are fit for causing some pathology It has been recommended that endothelial cells are basic in the advancement of HFRS and HPS. This theory depends on the way that in posthumous tissue endothelial cells are regularly found to communicate hantavirus antigens. Moreover, expanded penetrability of the microvascular endothelium was seen in tissues from lethal HFRS and HPS cases. In any case, systems of hantavirus caused endothelium penetrability stay obscure, since no endothelium harm due to hantavirus replication has been exhibited in posthumous tissue. Hantaviruses are not cytopathic in vitro. In vitro hantavirus disease does not influence endothelial cell monolayer penetrability. Together, these information recommend that the pathogenesis of HFRS and HPS is probably a multifunctional measure and incorporates endothelial cell harm, safe effectors, cytokines and chemokines, and so forth [17,24,25].

Utilizing DNA-Array investigation, a few labs have demonstrated that in vitro endothelial cell reactions are seriously adjusted in hantavirus-tainted cells for instance; articulation of 14-18 host qualities was up-directed in endothelial cells 3 hours after disease with PHV and SNV. Significantly more qualities were found up-controlled in endothelial cells 12 hours after HPV and SNV contamination. Our information additionally recommended that a bigger number of qualities were up-managed in endothelial cells tainted with pathogenic SNV when contrasted with non-pathogenic PHV. Articulation of numerous qualities was changed counting putative enemy of viral components, record factors, development factors, chemokines, receptors, basic proteins, INF inducible qualities and explicit kinases. Enactment of these qualities required hantavirus replication and didn't depend on acceptance of endogenous[26,27,28]. 
International Journal of Pharma Research and Health Sciences, 2021; 9 (1): 3280-3285

We have indicated that hantavirus enactment of the MxA, an INF-inducible protein, relies upon the cell type. Apparently, enactment of MxA conversely connects with the proficiency of hantavirus replication in lenient cells. These discoveries propose that hantavirus replication can be directed by enactment of INF-inducible cycle. In any case, there are two INF-inducible pathways, including 2-5" oligoadenylate synthetase (OAS) and IFN-inducible RNA-subordinate protein serine/threonine kinase (PKR), which may control hantavirus replication. Utilizing miniature clusters, it has been illustrated that few OAS qualities are initiated in hantavirus tainted endothelial cells, while no progressions were found in PKR quality articulation. More contemplates are expected to decide function of OAS and PKR in hindrance of hantavirus replication in endothelial cells[29,30].

\section{DIAGNOSTIC AND SEROLOGICAL TEST}

Different serological tests are presently utilized for the identification of antibodies framed against Old World hantaviruses by tainted people. One regular methodology is to perform standard immunofluorescence tests utilizing serum drawn from a patient, related to fluorescein- named goat against human antibodies, and slides containing hantavirus-tainted cells. Immunoglobulin $M$ and $\mathrm{IgG}$ enzymelinked immunosorbent tests are frequently used. Because cross-killing essential counter acting agent against a few Old-World hantavirus genotypes is framed during HFRS, it is normally unrealistic to recognize the causative infection species by serology without extra testing by other methods. Currently, sub-atomic tests in view of settled converse transcriptase-polymerase chain response (RTPCR) methodology that have been streamlined for the location of Old-World hantaviruses are supported for this purpose. RNA for these examines is commonly cleansed from entire blood or serum [26, 31, 32].

Various distinctive research facility tests are needed to make a last conclusion for HPS, even on account of SNV induced HPS, which presents with trademark highlights. Because of the low predominance of hantavirus antibodies in everybody of the United States, the best and generally utilized test for screening American patients is the $\mathrm{Ig} \mathrm{M}$ catch catalyst connected immunosorbent measure, which distinguishes IgM in all intense cases. Reverse transcriptase-PCR tests are valuable for both HFRS and HPS in light of the fact that the viral genotype can be distinguished on the off chance that the PCR item is sequenced and the subsequent information might be of epidemiological worth. Attributable to the risky nature of hantaviruses and the threats presented by mist concentrates shaped during different research facility strategies, tissues furthermore, serum examples for serological or sub-atomic tests are dealt with in biosafety cupboards in biosafety level 3 appraised research centers. Infection confinement is likewise acted in BSL-3 or BSL-4 offices; however, it is troublesome furthermore, typically wasteful and not regularly performed by clinical labs. A valuable demonstrative instrument in future endeavors at infection separation from people is to utilize serum taken from seropositive HPS patients to screen for infection creation in VERO E6 cells utilizing an immunofluorescence test $[30,33,34]$.

\section{TREATMENT AND PREVENTION}

At present, there is no particular treatment for HFRS and HPS. Treatment is basically steady and depends on the experience of the doctor. A few medications have been attempted with different impacts including IFN- $\alpha$, steroids, and cyclophosphamide. Ribavirin treatment was appeared to altogether diminish death rate when administrated right on time after the beginning of HFRS. Notwithstanding, ribavirin was insufficient for the treatment of HPS in the cardiopulmonary stage. Without powerful treatment, treatment of HFRS and HPS transfers on cautious liquid administration, hemodynamic observing, and control of electrolyte balance. Ribavirin is frequently utilized in the treatment of hantavirus sickness in the individual's republic of china and facility preliminaries there have indicated that ribavirin treatment can altogether diminish the death rate in HFRS whenever given in the initial 5 days after beginning. The utilization of $\alpha$-interferon has been appeared to have no impact on mortality and insignificant effect on clinical source. The utilization of tragacanthin polysaccharides has been proposed as likely restorative way to deal with hantavirus illness, so these mixes have been appeared to have antiviral movement against bunyavirus disease in mice[26,35,36].

An assortment of immunizations has been created by utilization of both slaughtered infection and recombinant DNA innovation. Formalin-inactivated immunizations have been appeared to deliver killing immunizer and determined antibody ensured infant mice. Such immunizations have been demonstrated to be protected and immunogenic. Recombinant immunizations have additionally been created. Approaches using baculovirus and infection communicated viral glycoproteins have been appeared to ensure against challenge in creature models $[37,38]$.

Financially accessible inactivated immunization, "Hantavax", has indicated a $97 \%$ seroconversion rate in human volunteers one month after inoculation. Reimmunization actuated solid counter acting agent reactions in 94 to $100 \%$ of antibody beneficiaries. Half of the inoculated populace uncovered the nearness of killing antibodies 1 year later. It has been presumed that "Hantavax" immunization is all around endured and there are no obvious contrasts in the reactions between various people[31].

The backbone of treatment in all genuine Hantavirus infection is general steady treatment. Upkeep of intravascular volume and cardiovascular yield with inotropic uphold if fundamental and the executives of liquid and electrolyte balance are the principle components of this 
International Journal of Pharma Research and Health Sciences, 2021; 9 (1): 3280-3285

methodology. The utilization of intense peritoneal dialysis and hemodialysis can be life-sparing. Blood gas observing and utilization of mechanical ventilation and oxygen are most significant viewpoints. Extracorporeal film oxygenation has been discovered valuable as a rescue treatment in patients [39].

Possibly the best methods for control of Hantavirus illness are by restricting contact with rodents and their feces. Correspondingly, working practices and conditions in farming, ranger service and military exercises ought to be altered where conceivable to lessen human rat presentation. General safety measure for occupants living in influenced territories have been created and manage disposal of rodents inside the home and decrease in rat food and haven close to homes. In research center creature offices, all lab work including the propagation of hantavirus in cell culture or creatures ought to be led in biosafety level conditions. For the most part exclusive expectations of creature husbandry and adherence to wellbeing conventions must be utilized when managing exploratory creatures. Even in work with creatures not known to be tainted with Hantavirus, conventions ought to limit possible contact with discharges $[2,40]$.

\section{CONCLUSION}

In the course of recent many years, the agreement and acknowledgment of Hantaviral contaminations through the world has extraordinarily improved. The number of perceived infections continues to increment, as does the range of Hantaviral diseases. Natural changes may influence the elements of the rat carrier and transmission of Hantavirus infections. There is as yet far to go to locate a viable treatment for Hantavirus infections, and the drawn out anticipation of Hantaviral diseases and the pathogenicity of certain infection species stay to be set up. However genuine assurance will require a protected and successful multivalent antibody or an immunization adjusted

to neighborhood conditions

\section{REFERENCES}

1. Kruger DH, Figueiredo LT, Song JW, Klempa B. Hantaviruses-Globally emerging pathogens. J Clin Virol 2015; 64: 128-36.

2. Krüger DH, Schönrich G, Klempa B. Human pathogenic hantaviruses and prevention of infection. Hum Vaccin 2011; 7: 685-93.

3. Noor R. General awareness on hantavirus infection: A brief review. Biomed Biotechnol Res. J 2020; 4: 274.

4. Jonsson CB, Figueiredo LT, Vapalahti O. Global Perspective on Hantavirus Ecology, Epidemiology, and Disease. Clin Microbiol Rev 2010; 23: 412-41.

5. Plyusnin A, Vapalahti O, Vaheri A. Hantaviruses: genome structure, expression and evolution. J Gen Virol 1996; 77: 2677-87.
6. Johnson KM, Hantaviruses: History and Overview. in Hantaviruses, eds. Schmaljohn, C. S. \& Nichol, S. T.; Springer Berlin Heidelberg 2001; 256: 1-14.

7. Simmons J H \& Riley L K. Hantaviruses: an overview. Comp Med 2002; 52: 97-110.

8. Plyusnin A. Genetics of hantaviruses: implications to taxonomy. Arch Virol 2002; 147: 665-82.

9. Dearing MD, Dizney L. Ecology of hantavirus in a changing world: Ecology of hantavirus in a changing world. Ann N Y Acad Sci 2010; 1195: 99-112.

10. Klempa B. Hantaviruses and climate change. Clin Microbiol Infect 2009; 15: 518-23.

11. $\mathrm{Yu} \mathrm{X}, \mathrm{Tesh} \mathrm{RB}$. The role of mites in the transmission and maintenance of Hantaan virus (Hantavirus: Bunyaviridae). J Infect Dis 2014; 210: 1693-9.

12. Milholland MT, Castro-Arellano I, Suzán G, GarciaPeña GE, Lee TE, Rohde RE, et al. Global Diversity and Distribution of Hantaviruses and Their Hosts. EcoHealth 2018; 15: 163-208.

13. Holmes EC, Zhang YZ. The evolution and emergence of hantaviruses. Curr Opin Virol 2015; 10: 27-33.

14. Young JC, Mills JN, Enria DA, Dolan NE, Khan AS, Ksiazek TG. New World hantaviruses. Br Med Bull 1998; 54: 659-73.

15. Schmaljohn C, Hjelle B. Hantaviruses: a global disease problem. Emerg Infect Dis 1997; 3: 95-104.

16. Mittler E, Dieterle ME, Kleinfelter LM, Slough MM, Chandran K, Jangra RK. Hantavirus entry: Perspectives and recent advances. Adv Virus Res 2019; 104: 185224.

17. Munir N, Jahangeer M, Hussain S, Mahmood Z, Ashiq M, Ehsan F, et al. Hantavirus diseases pathophysiology, their diagnostic strategies and therapeutic approaches: A review. Clin Exp Pharmacol Physiol 2021; 48: 20-34.

18. Hjelle B, Jenison SA, Goade DE, Green WB, Feddersen RM, Scott AA, et al. Hantaviruses: Clinical, Microbiologic, and Epidemiologic Aspects. Crit Rev Clin Lab Sci 1995; 32: 469-508.

19. Avšič-Županc T, Saksida A, Korva M. Hantavirus infections. Clin Microbiol Infect 2019; 21: e6-e16.

20. Liu R, Ma H, Shu J, Zhang Q, Han M, Liu Z, et al. Vaccines and Therapeutics Against Hantaviruses. Front Microbiol 2020; 10: 2989.

21. Clement J, Mc Kenn P, Groen J, Osterhaus AD, Colson $\mathrm{P}$, Vervoort $\mathrm{T}$, et al. Epidemiology And Laboratory Diagnosis Of Hantavirus (Htv) Infections. Acta Clin Belg 1995; 50: 9-19.

22. Yanagihara R, Gu SH, Arai S, Kang HJ, Song JW. Hantaviruses: Rediscovery and new beginnings. Virus Res 2014; 187: 6-14.

23. Hart CA, Bennett M. Hantavirus infections: epidemiology and pathogenesis. Microbes Infect 1999; 1: 1229-37. 
International Journal of Pharma Research and Health Sciences, 2021; 9 (1): 3280-3285

24. Muranyi W, Bahr U, Zeier M, van der Woude FJ. Hantavirus Infection. J Am Soc Nephrol 2005; 16: 3669-79.

25. Lednicky JA. Hantaviruses. a short review. Arch. Pathol. Lab Med 2003; 127: 30-5.

26. Kharche A, Gorde N, Waghulde S, Chandekar A, Tekade B, Kale M. Hantavirus- A Challenge Of Prevention. Int J Sci Res Eng Dev 2020; 3: 11.

27. Hangaragi P S. Hantavirus: An emerging global threat. Asian J Oral Health Allied Sci 2020; 10: 4.

28. Zaki SR. Hantavirus pulmonary syndrome. Pathogenesis of an emerging infectious disease. Am J Pathol 1995; 146: 552-79.

29. Simmons JH, Riley L K. Hantaviruses: An Overview. Comp Med 2002; 52: 14.

30. Hart CA, McCAUGHEY C. Hantaviruses. J Med Microbiol 2000; 49: 587-99.

31. Bi Z, Formenty PBH, Roth C E. Hantavirus Infection: a review and global update. J Infect Dev Ctries 2008; 2: 003-23.

32. Jenison S, Hjelle B, Simpson S, Hallin G, Feddersen R, Koster F. Hantavirus pulmonary syndrome: clinical, diagnostic, and virologic aspects. Semin. Respir Infect 1995; 10: 259-69.

33. Manigold T, Vial P. Human hantavirus infections: epidemiology, clinical features, pathogenesis and immunology. Swiss Med. Wkly. 2014; 144: w13937.

34. Mattar S, Guzmán C, Figueiredo LT. Diagnosis of hantavirus infection in humans. Expert Rev Anti Infect Ther 2015; 13: 939-46.

35. Brocato RL, Hooper JW. Progress on the Prevention and Treatment of Hantavirus Disease. Viruses 2019; 11: 610.

36. Dheerasekara K, Sumathipala S, Muthugala R. Hantavirus Infections-Treatment and Prevention. Curr Treat Options Infect Dis 2020; 12: 410-21.

37. Maes P, Clement J, Gavrilovskaya I, Van Ranst M. Hantaviruses: Immunology, Treatment, and Prevention. Viral Immunol 2004; 17: 481-97.

38. Hjelle B. Vaccines against hantaviruses. Expert Rev Vaccines 2002; 1: 373-84.

39. Akram SM, Mangat R, Huang B, Hantavirus Cardiopulmonary Syndrome. in StatPearls; StatPearls Publishing, 2020.

40. Krüger DH, Ulrich R, Lundkvist A. Hantavirus infections and their prevention. Microbes Infect 2001; 3: 1129-44.
CONFLICT OF INTEREST: The authors declare no conflict of interest, financial or otherwise.

SOURCE OF FUNDING: None.

AVAILABILITY OF DATA AND MATERIALS: Not applicable.

CONSENT FOR PUBLICATION: Not applicable.

ETHICS APPROVAL AND CONSENT TO PARTICIPATE: Not applicable.

HUMAN AND ANIMAL RIGHTS: No animals/humans were used for this study. 